BMJ Open Sport \& Exercise Medicine

\section{Why a new sports and exercise medicine journal for clinicians?}

To cite: Khan K. Why a new sports and exercise medicine journal for clinicians?. BMJ Open Sport Exerc Med 2015;1:e000002. doi:10.1136/bmjsem-2015000002

- Prepublication history and additional material for this paper is available online. To view these files please visit the journal online (http://dx.doi.org/10.1136/ bmjsem-2015-000002).

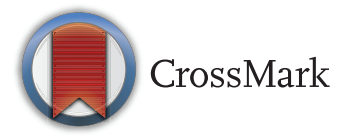

School of Industrial Relations, University of Montreal, Montreal, Quebec, Canada

Correspondence to Karim Khan; karim.khan@ ubc.ca
There has been a massive expansion of sports medicine knowledge since BJSM was launched in 1966. 'Journals' themselves have transformed into media channels. In 2015, the target audience in sports and exercise medicine consists of physiotherapists, sports therapists, sport rehabilitators and trainers, athletic trainers, strength and conditioning coaches, as well as the doctors who founded BJSM.

Quality (read that as an antonym to "predatory') Open journals play an important role in sports and exercise medicine. They provide quality control (peer review) and a convenient location for information that cannot be included in the top-rated journals. For example, BJSM can accept only $8 \%$ of submissions of original data papers $(30 \%$ of review papers). Other journals in the 'Big 3' have similar acceptance rates.

BMJ publishing is a leading clinical publishing company with experience in all aspects of modern publishing. It has experience in Open publishing and BMJ Open is a flagship in the field. We look forward to BMJ publishing guidance to provide a valuable asset for clinicians-BMJ Open Sports $\mathcal{E}$ Exercise Medicine (BOSEM).

\section{WHAT SORT OF PAPERS WILL 'BOSEM' ACCEPT?}

Physiotherapists/physical therapists, sports therapists, sport rehabilitators and trainers, athletic trainers, strength and conditioning coaches as well as the doctors are the target audience for BOSEM; papers that will appeal to this audience will be considered.

Taking our lead from the flagship $B M J$ Open, we focus on research relevant to patients and clinicians. We will not publish 'studies conducted on animals, laboratory studies not linked to patient outcomes, papers reporting solely physiological or biomechanical results from healthy participants, anatomy, cell biology or non-clinical psychology'.

We will consider study protocols, phase I trials and meta-analyses. Studies reporting negative results are not at a disadvantage at BOSEM. Case reports should be submitted to BMJ Case Reports.

As with BJSM, BOSEM will aim to continually provide better and better value for our community-so there will be changes as we get our feet wet, learn more and receive sage advice. 